This item was submitted to Loughborough's Research Repository by the author.

Items in Figshare are protected by copyright, with all rights reserved, unless otherwise indicated.

\title{
A comparison of on-road aerodynamic drag measurements with wind tunnel data from Pininfarina and MIRA
}

PLEASE CITE THE PUBLISHED VERSION

http://dx.doi.org/10.4271/980394

PUBLISHER

(C) SAE International

VERSION

VoR (Version of Record)

\section{LICENCE}

CC BY-NC-ND 4.0

\section{REPOSITORY RECORD}

Le Good, G.M., Martin A. Passmore, and A. Cogotti. 2010. "A Comparison of On-road Aerodynamic Drag Measurements with Wind Tunnel Data from Pininfarina and MIRA". figshare. https://hdl.handle.net/2134/6707. 


\section{A Comparison of On-Road Aerodynamic Drag Measurements with Wind Tunnel Data from Pininfarina and MIRA}

G. M. Le Good and J. P. Howell

Rover Group Limited

M. A. Passmore

Loughborough University

A. Cogotti

Industrie Pininfarina SpA

Reprinted From: Developments in Vehicle Aerodynamics

(SP-1318) 
The appearance of this ISSN code at the bottom of this page indicates SAE's consent that copies of the paper may be made for personal or internal use of specific clients. This consent is given on the condition, however, that the copier pay a $\$ 7.00$ per article copy fee through the Copyright Clearance Center, Inc. Operations Center, 222 Rosewood Drive, Danvers, MA 01923 for copying beyond that permitted by Sections 107 or 108 of the U.S. Copyright Law. This consent does not extend to other kinds of copying such as copying for general distribution, for advertising or promotional purposes, for creating new collective works, or for resale.

SAE routinely stocks printed papers for a period of three years following date of publication. Direct your orders to SAE Customer Sales and Satisfaction Department.

Quantity reprint rates can be obtained from the Customer Sales and Satisfaction Department.

To request permission to reprint a technical paper or permission to use copyrighted SAE publications in other works, contact the SAE Publications Group.

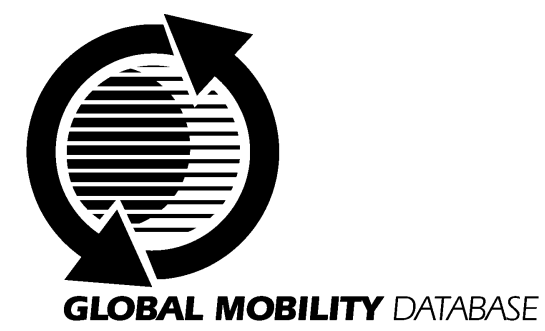

All SAE papers, standards, and selected books are abstracted and indexed in the Global Mobility Database

No part of this publication may be reproduced in any form, in an electronic retrieval system or otherwise, without the prior written permission of the publisher.

\section{ISSN 0148-7191}

Copyright 1998 Society of Automotive Engineers, Inc.

Positions and opinions advanced in this paper are those of the author(s) and not necessarily those of SAE. The author is solely responsible for the content of the paper. A process is available by which discussions will be printed with the paper if it is published in SAE Transactions. For permission to publish this paper in full or in part, contact the SAE Publications Group.

Persons wishing to submit papers to be considered for presentation or publication through SAE should send the manuscript or a 300 word abstract of a proposed manuscript to: Secretary, Engineering Meetings Board, SAE.

\section{Printed in USA}




\title{
A Comparison of On-Road Aerodynamic Drag Measurements with Wind Tunnel Data from Pininfarina and MIRA
}

\author{
G. M. Le Good and J. P. Howell \\ Rover Group Limited \\ M. A. Passmore \\ Loughborough University \\ A. Cogotti \\ Industrie Pininfarina SpA
}

Copyright (c) 1998 Society of Automotive Engineers, Inc.

\begin{abstract}
The principal development tool for the vehicle aerodynamicist continues to be the full-scale wind tunnel. It is expected that this will continue for many years in the absence of a reliable alternative.

As a true simulation of conditions on the road, the conventional full-scale wind tunnel has limitations. For example, the ground is fixed relative to the vehicle, allowing an unrepresentative boundary layer to develop, and the wheels of the test vehicle do not rotate. These limitations are known to influence measured aerodynamic data.
\end{abstract}

In order to improve the representation of road conditions in the wind tunnel, most of the techniques used have attempted to control the ground plane boundary layer. Only at model scale has the introduction of a moving ground plane and rotating wheels been widely adopted.

The Pininfarina full-scale wind tunnel now incorporates the Ground Effect Simulation System which allows testing with a moving belt and rotating wheels. A major feature of this facility is that test vehicles can be easily installed with only minor modifications.

This paper compares aerodynamic drag measurements for a large saloon, in various configurations, obtained both in the wind tunnel and on the road. The wind tunnel results are presented for various ground simulations. These are: moving belt with rotating wheels and stationary belt with fixed wheels at Pininfarina, and the conventional fixed ground in the MIRA full-scale wind tunnel. The on-road data is derived from coastdown tests.

\section{INTRODUCTION}

During the 1980s automobile manufacturers achieved a significant reduction in the aerodynamic drag of passenger cars largely through the optimisation of upper-body shapes. Although this trend has slowed during the 1990s, continued reduction in aerodynamic drag will be necessary if passenger cars are to meet increasingly stringent exhaust emission targets being set by western governments. This is particularly true for carbon dioxide output which is seen as a major contributor to the problem of global warming. Although aerodynamic drag reduction may be less important than weight reduction in lowering carbon dioxide output, it remains an important element in vehicle design because it is an achievable gain, and this is still true even though the drive cycle, over which these emissions are measured, predominantly simulates urban usage. Carbon dioxide output is measured in the same way as fuel consumption, with vehicles running on a dynamometer, using resistance values generated from road load data. The vehicle aerodynamicist must ensure that the drag reductions are realistically achievable on the road and not just in the wind tunnel.

Traditionally, passenger car aerodynamic drag development is carried out in the wind tunnel which provides a controlled and repeatable environment for testing. In the conventional full-scale aerodynamic test, in which the vehicle is located on the floor of the wind tunnel working section, the true boundary conditions at the ground surface are not satisfied. The boundary layer, which develops on the fixed floor, is unrepresentative of ground conditions experienced on the road. 
Copyright (C) 1998 SAE International. This paper is posted on this site with permission from SAE International, and is for viewing only. Further distribution and use of this paper is not permitted withoul permission from $S A E$. In addition, the wheels do not rotate in the conventional wind tunnel test and thus the drag of the wheels alone will be in error. The vehicle body will also experience modified flows into and out of the wheel arches and the energy losses due to wheel rotation will not be present. Early studies of the aerodynamic effects of wheel rotation were reviewed by Cogotti (1). More recently work has been completed by Bonis (2), Mercker et al (3-6), Wiedemann (7) and Zwicker et al (8). All the authors have shown that total vehicle drag is reduced with rotation of the wheels.

To complicate the situation, there is only poor agreement in drag measurement between wind tunnels. Correlation tests carried out in the early 1980s (9-12) showed an approximate $5 \%$ variation in drag coefficient values, but since then a number of wind tunnels have been commissioned and the spread has widened (18). Not only is there variation in absolute drag values, there is also scatter in the drag difference due to configuration change $(9$, $12,13)$.

While the lack of complete simulation of road conditions in wind tunnels is widely recognised, the need to actually achieve this in order to meet drag reduction objectives remains subject to debate. Currently, the focus of drag reduction remains the upper-body and the need for improved simulation is not proven. In the future, however, drag reduction from refinement of underfloor features will be necessary. Where evaluation of the underbody features is required, an improved simulation is increasingly seen as essential, even for cars with conventional ground clearances.

Techniques for the improvement of the simulation of road conditions in full-scale wind tunnels were initially concentrated on the reduction or removal of the ground-plane boundary layer. True ground simulation, however, can only be provided by the use of a moving belt. While moving ground systems have been popular for scale model testing, particularly of racing cars, the complication of replicating the technique at full-scale has precluded it's wide-scale adoption. Work published by Mercker et al (4), however, has shown some significant differences in drag performance using the full-scale moving ground system at DNW. The basic limitation of this technique remains the need to significantly modify the test vehicle prior to wind tunnel testing. An alternative approach which allows the testing of any vehicle over a moving ground plane with only minor modifications has become available at Pininfarina (14). In this system a narrow width belt enables a relatively simple installation of the test vehicle.

While a significant amount of published data exists to examine alternative ground plane simulation techniques in full-scale wind tunnels, there remains comparatively little published data correlating wind tunnel results with track derived data. This is because track test methods are complicated and time-consuming to perform. Buckley (15) and Passmore (16) have both, however, used advanced coastdown tests to derive aerodynamic drag data from the road. These techniques have sufficient resolution and repeatability to enable correlation between track and wind tunnel data (17).

In this paper the coastdown technique is used specifically to compare track derived data with that from both the Pininfarina full-scale moving ground wind tunnel and from the conventional fixed ground wind tunnel at MIRA.

\section{TEST VEHICLE AND CONFIGURATIONS}

The test vehicle used in this investigation was a 1990 Model Year Rover 820Si saloon, as shown in Figure 1, and was the same vehicle as used during previously reported work (17).

Systematic aerodynamic changes to the over-body shape were achieved by the use of simple add-on devices. The first series comprised three boot spoilers which were geometrically similar but of increasing size, as shown schematically in Figure 2.

Changes to the underbody were achieved by the use of aluminium panels to give a smooth underfloor. These are shown in Figure 3 and were designed to simply cover the existing floor. They were not aerodynamically optimised. Tests were conducted for the full underfloor covering in conjunction with the boot spoilers described above and the extent of underfloor smoothing was also varied.

A further systematic test was conducted on the base vehicle using a series of simple front spoilers fitted to the lower edge of the front bumper, as shown in Figure 4. 
Copyright $\odot 1998$ SAE International. This paper-is posted on this site with permission from SAE International, and is for viewing only. Further distribution and use of this paper is not permitted withoul permission from ${ }^{2} \mathrm{SA} E$.

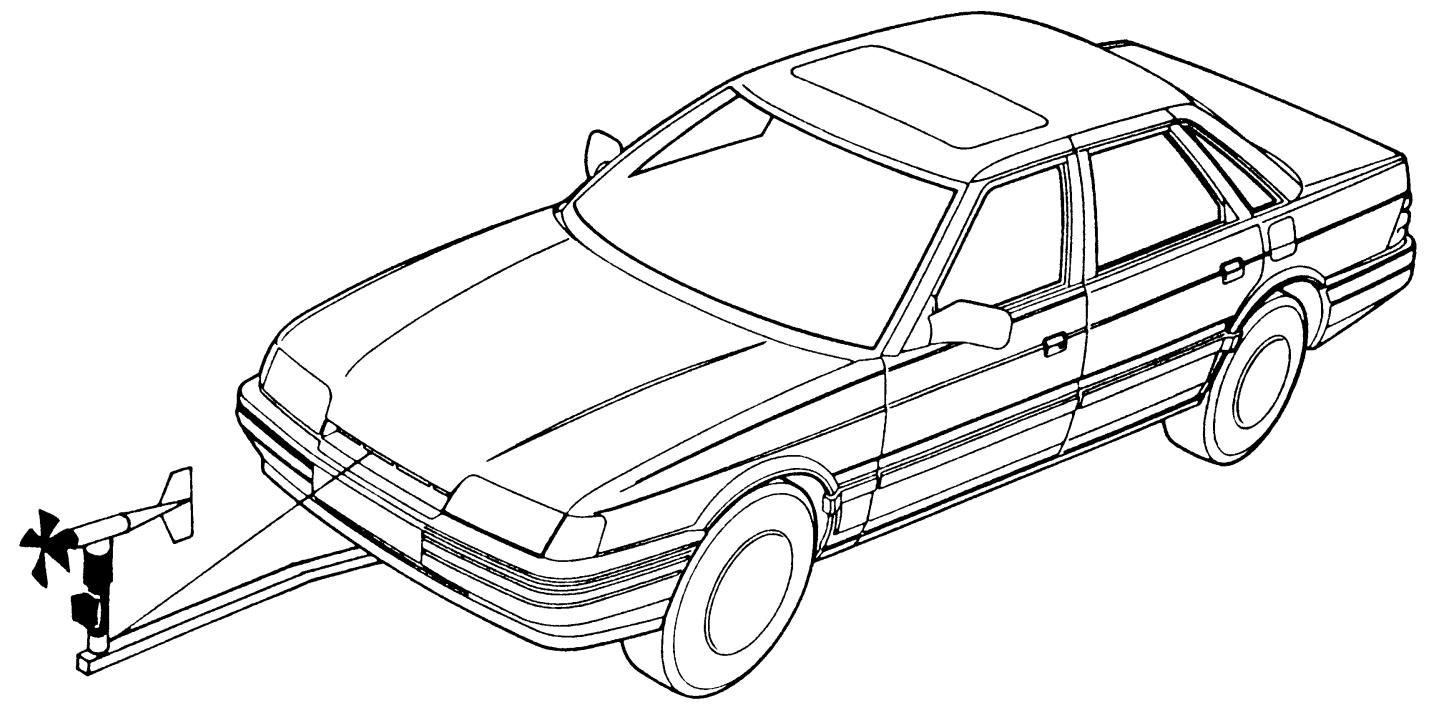

Figure 1. Rover 820Si test vehicle with rotating vane anemometer


Figure 2. Boot spoiler series

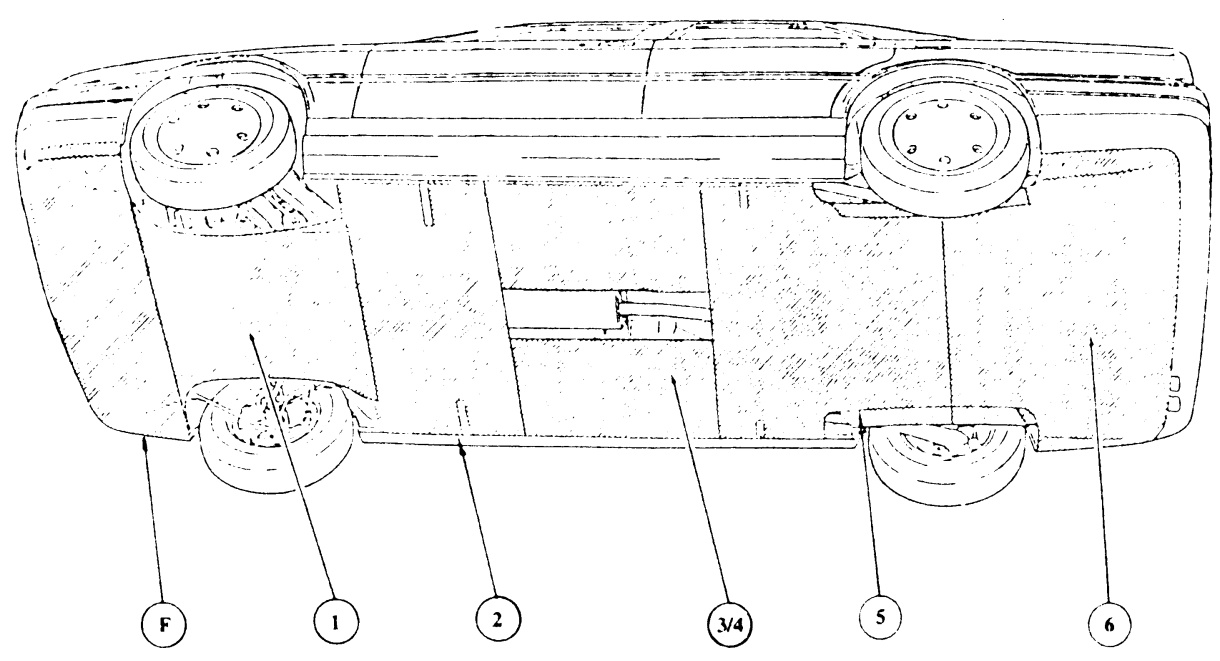

Figure 3. Rover 820Si underfloor panels
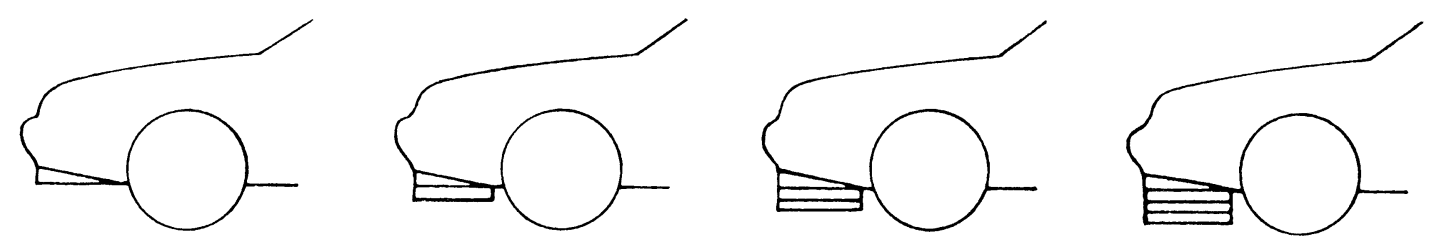

Figure 4. Front spoiler series 
TEST PRINCIPLES - There are two established test techniques for measuring total vehicle drag (i.e. the sum of aerodynamic drag, rolling resistances and mechanical losses) on the road. These are the steady state and the coastdown techniques and both are recognised as methods for the determination road loads for chassis dynamometers used in emission testing.

In aerodynamic research, the coastdown technique has been favoured by Buckley (15) and Passmore (16). It should be noted, however, that the coastdown technique used here is an advanced method capable of accurately separating the drag contributions.

A detailed description of the aerodynamic coastdown technique adopted for this work, developed by Passmore, can be found in (16) but the basic principles are as follows. The vehicle is driven up to the maximum speed required, shifted into neutral and then allowed to freely decelerate. Since there is no tractive effort, the deceleration of the test vehicle, by a simple application of Newton's second law, is proportional to the sum of the aerodynamic drag force, the rolling resistance of the tyres and the mechanical losses.

Mechanical losses arise from the transmission (due to oil churning and the bearings) and the undriven wheels. Separate tests in the laboratory were conducted to measure these losses directly. The transmission losses were subsequently modelled for the purposes of analysis, as described below, using a quadratic in speed and the undriven wheel losses as a constant plus speed dependent term (16).

During coastdown testing, maximum speeds were below $36 \mathrm{~m} / \mathrm{s}(130 \mathrm{~km} / \mathrm{h})$ and in this region tyre rolling resistance can be represented by a linear function which is temperature dependent. This was supported by data from the relevant tyre manufacturer.

The coastdown analysis is also described in (16) and enables four coefficients of aerodynamic drag and tyre rolling resistance to be determined by fitting a mathematical model to measured coastdown time-history data. In the analysis, the coastdown model, is integrated to simulate a coastdown speed-time profile. Wind data is input to the model during the integration. The simulated coastdown curve is then fitted to the measured data using a non-linear optimisation procedure in order to achieve a least squares fit.

The wheel aerodynamic torque is included in the aerodynamic drag term, since the transmission loss test is performed using solid discs (in place of the wheels and tyres) to eliminate wheel aerodynamic torque effects from the measured transmission losses.

COASTDOWN INSTRUMENTATION - For the track tests, the vehicle was instrumented to measure road speed, airspeed and yaw angle. This instrumentation was also fitted during the wind tunnel tests to ensure that the

\section{method.}

Since ambient conditions can have a large influence on the results, airspeed and aerodynamic yaw angle were measured by means of a combined propeller and vane anemometer mounted on a boom extending $1.5 \mathrm{~m}$ from the front of the vehicle, as shown in Figure 1. The vehicle speed was measured using an electromagnetic pick-up on a slotted standard brake disc. A total of 100 slots were used to give a smooth speed signal output. Using an onboard computer running proprietary data acquisition software, the continuous measurements of airspeed, yaw angle and vehicle speed were sampled at $5 \mathrm{~Hz}$ during the deceleration phase and stored for later analysis.

In order to accurately correct for the driveline losses, the transmission oil temperature was also recorded during the test using a thermocouple fitted via the sump drain plug.

COASTDOWN TESTING - The coastdown tests were conducted on the horizontal two-way straights at the MIRA Proving Ground in the UK. The following test procedure was developed to ensure maximum repeatability.

Prior to testing, the vehicle was weighed, the tyre pressures set to the equivalent of 1.93 bar at $20 \mathrm{deg} C$ and the vehicle static trim heights measured. From cold, the vehicle was then run on the test track at a steady speed of $22 \mathrm{~m} / \mathrm{s}(80 \mathrm{~km} / \mathrm{h})$ for 20 minutes to condition the tyres.

Coastdown runs were typically of 70 seconds duration and starting speeds were either $34.7 \mathrm{~m} / \mathrm{s}(125 \mathrm{~km} / \mathrm{h})$ or $29.2 \mathrm{~m} / \mathrm{s}(105 \mathrm{~km} / \mathrm{h})$. Approximately one third of the runs for a particular configuration were started at the lower speed to aid more accurate determination of the tyre characteristics by the analysis software. By the end of the test runs the vehicle speed had reduced to between 16.7 $\mathrm{m} / \mathrm{s}(60 \mathrm{~km} / \mathrm{h})$ and $5.6 \mathrm{~m} / \mathrm{s}(20 \mathrm{~km} / \mathrm{h})$. In the analysis routine, a constant $C_{d}$ with speed was assumed. 10 runs in each direction (i.e. a total of 20) were performed for each aerodynamic configuration with runs grouped as pairs for the purposes of anemometer calibration (16).

At the end of a series of tests the static trim heights were re-measured to ensure vehicle consistency. The weight of the vehicle was also checked for use in the analysis. A linear reduction of weight (due to fuel usage) with distance travelled was assumed.

\section{WIND TUNNEL TESTING AT PININFARINA}

The Pininfarina wind tunnel, originally opened in 1973 , is of the open-jet working section design with a closed return. The nozzle has an exit area of $11.75 \mathrm{~m}^{2}$ and a contraction ratio of $6.5: 1$. The length of the test section is $8 \mathrm{~m}$ with a width of $9.6 \mathrm{~m}$ and height $4.2 \mathrm{~m}$. The collector has a cross-sectional area of $17.33 \mathrm{~m}^{2}$. The blockage ratio of the Rover $820 \mathrm{Si}$ in the Pininfarina wind tunnel was $17 \%$, based on the nozzle exit area and significantly below the maximum limit of $25 \%$. 
Copyright ( 1998 SAE International. This paper-is posted on this site withpermission from SAE International, and is for viewing only. Further distribution and use of this paper is not permitted withoul permission from $S A E$.

A full-scale moving ground plane was installed in this facility during 1993/94 and consists of a $1 \mathrm{~m}$ wide moving belt, $3.8 \mathrm{~m}$ long (between roller axes), running within the balance turntable. The narrow width belt was specifically chosen during the design of the system to enable most passenger cars to be tested over a moving ground plane with minimal modification.

In order to achieve rotation of the wheels, they are positioned on small powered rollers mounted within the balance system. The rollers can be adjusted to suit the track and wheelbase dimensions of the test vehicle and are able to match wheel rotation with belt speed. They had a diameter of $200 \mathrm{~mm}$ and were $50 \mathrm{~mm}$ wide (these have since been replaced by rollers $135 \mathrm{~mm}$ wide). These rollers can also be used independently of the movement of the belt enabling some separation of moving ground and wheel rotation effects. The vehicle is restrained using four clamps from the balance onto the sill section of the test vehicle.

In order to test over the moving ground plane, the only modifications required to the test vehicle are the temporary removal of the road springs and the fixing provision in the sills for the clamps.

Since the moving belt is relatively narrow and short, a tangential blowing system is installed at the end of the nozzle. This blowing system provides a flat velocity profile of the boundary layer immediately upstream of the moving belt. The belt then carries this velocity profile along the underbody. This blowing system covers the area upstream of the moving belt and extends over the full width of the nozzle. In addition to the blowing system, the Pininfarina wind tunnel employs two further suction systems to reduce the floor boundary layer and enable the tangential blowing requirement to be kept to a minimum. With the tangential blowing and moving ground system in operation, the displacement thickness was $0 \mathrm{~mm}$ at the balance centre. For the stationary belt case, the displacement thickness was $7 \mathrm{~mm}$ at the balance centre. Further details of the Pininfarina facility are given in (14).

All testing of the aerodynamic configurations described above was conducted using the standard tunnel test speed of $39 \mathrm{~m} / \mathrm{s}(140 \mathrm{~km} / \mathrm{h})$. No corrections for blockage were made to the measured data. The configurations were also tested in both moving ground and stationary belt modes. In the stationary belt mode the tangential blowing system is not employed.

\section{WIND TUNNEL TESTING AT MIRA}

Wind tunnel testing during this investigation was also conducted in the MIRA full-scale wind tunnel using the standard passenger car test procedure. This facility is of the closed working section, open return type of wind tunnel design. The tunnel has a working section which is $15.24 \mathrm{~m}$ in length with a cross-sectional area of $34.93 \mathrm{~m}^{2}$. With a frontal area of $2.03 \mathrm{~m}^{2}$ the Rover $820 \mathrm{Si}$ test vehicle had a blockage of $5.8 \%$.
In the wind tunnel the vehicle sits on four small rectangular plates, flush with the floor, which can be adjusted in position to match the track and wheelbase dimensions of the test vehicle. The plates are connected to a six-component underfloor balance. The nominal wind tunnel test speed is $27 \mathrm{~m} / \mathrm{s}$.

No boundary layer control system is employed in the standard passenger car test procedure at MIRA, the displacement thickness being $17 \mathrm{~mm}$ on the tunnel floor at the balance. All the measured data is corrected for the effects of blockage using either the standard MIRA continuity method or Mercker volume correction. Drag data is also subject to a horizontal buoyancy correction.

In the wind tunnel the vehicle was restrained using the transmission and all four brakes, and ballasted to achieve the same static trim height condition as for the coastdown tests. With the wind on, the vehicle was free to float on its suspension in a similar manner to that encountered on the track.

A wind tunnel assessment of the influence of vehicle attitude on both drag and optimum geometry was undertaken to account for any effects arising from the change in pitch due to weight transfer on the decelerating vehicle during the coastdown tests. The maximum drag coefficient reduction is 0.001 and there is no change in the spoiler geometry for minimum drag. The effects of pitch can be ignored.

\section{RESULTS AND DISCUSSION}

BOOT SPOILER SERIES - Figure 5 shows the variation of absolute drag coefficient with boot spoiler height with the standard underfloor condition for the various test methods. The first point to note is that the general trend of drag increase with spoiler height is similar for all wind tunnel test methods. This is even more evident in Figure 6 where the incremental drag coefficient due to spoiler height is considered. In this case, all the test methods show good agreement in drag increases due to these over-body configuration changes.

The spread of coastdown data shown in Figure 5 arises from day-to-day repeatability. As expected for a track based test, day-to-day variation is greater than tunnel repeatability and is of the order of 0.01 . Variation within a single series of systematic tests performed on the same day, however, is within 0.005 allowing greater confidence to be used for the comparison of changes. Reducing the day-to-day variation in coastdown tests is the subject of on-going work.

Figure 5 also shows that in absolute terms, the mean coastdown data is on average 0.009 greater than the drag coefficient measured in the MIRA wind tunnel (using the standard continuity blockage correction) and equal to that in the Pininfarina wind tunnel with the stationary wheels and belt. For the moving ground case at Pininfarina, drag values were slightly lower than those with the stationary wheels and belt, a result which is consistent 
cker volume correction technique for blockage to the MIRA data gives results which are greater than the coastdown-derived data. This technique takes no account for the tunnel floor boundary layer or the absence of effects due to wheel rotation. The presence of the ground plane boundary layer is likely to reduce the measured drag because it effectively shields a portion of the tyres from the approach flow, whereas wheel rotation will have the opposite effect $(3-8,14)$.

Figure 7 shows the variation of absolute drag coefficient with boot spoiler height for the test vehicle fitted with a smooth underfloor. Comparing Figure 7 with Figure 5 it can be seen that with the smooth floor, there is an apparently greater change in drag with spoiler size than for the standard (rough) floor. Figure 7 shows reasonable agreement between the volume blockage corrected data from the MIRA wind tunnel and that obtained from the track tests. For the Pininfarina wind tunnel data, there is a noticeable difference between the absolute values for the stationary belt case and those for the moving ground condition. The moving ground drag coefficient values are on average 0.015 lower than the stationary belt condition. With the standard floor, as shown in Figure 5, there was only a small difference in absolute drag due to the ground simulation employed. The suggestion here is of a change in flow characteristics when the smooth floor is employed. The MIRA continuity corrected data lies between the two Pininfarina results, which is noticeably different to that of the rough floor case, as shown in Figure 5 .

Figure 8 shows the incremental drag coefficient due to boot spoiler height for the test vehicle fitted with the smooth underfloor. This shows that the change in drag with spoiler height as measured in the MIRA wind tunnel is similar to that obtained from the track tests. For the Pininfarina results, the drag increase with spoiler height is less, irrespective of belt motion.

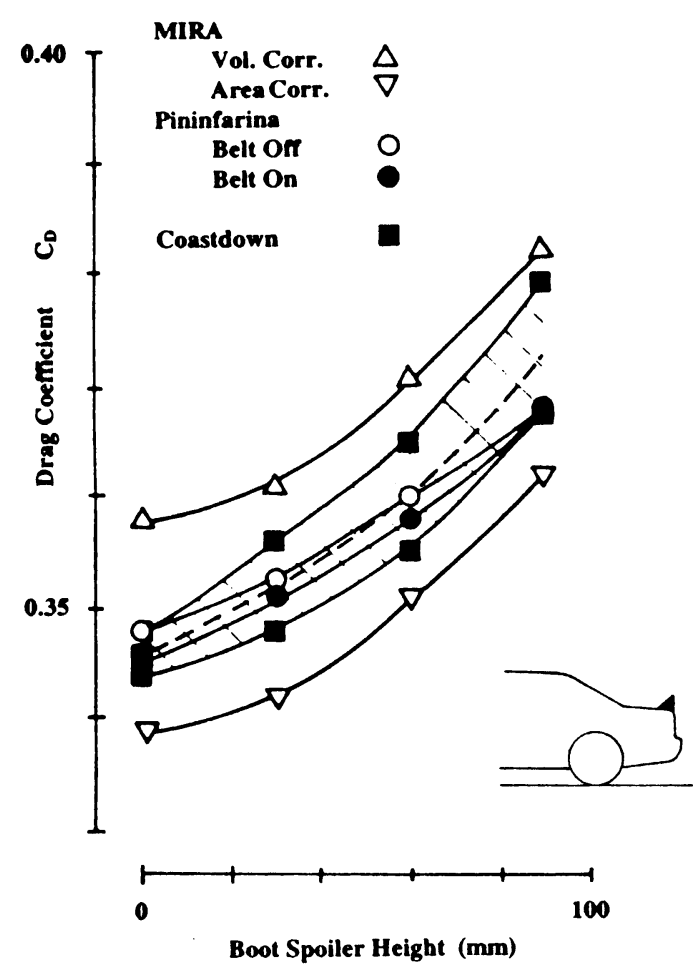

Figure 5. Effect of boot spoilers - rough floor



Figure 6. Incremental effect of boot spoilers - rough floor 


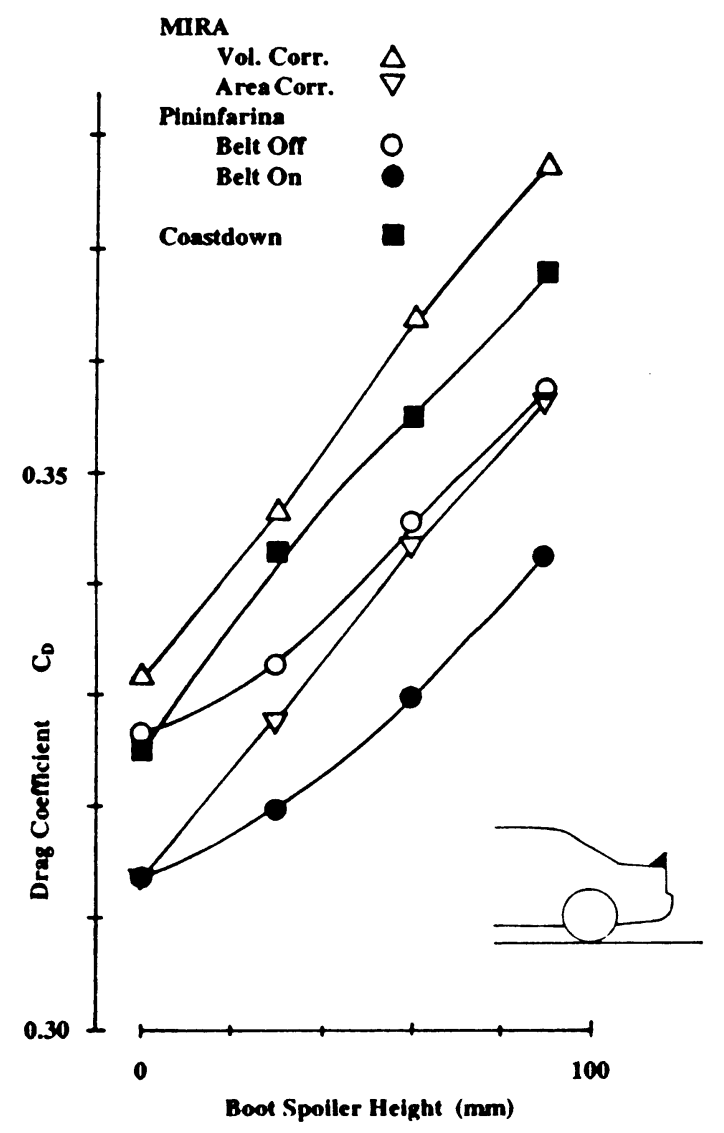

Figure 7. Effect of boot spoilers - smooth floor

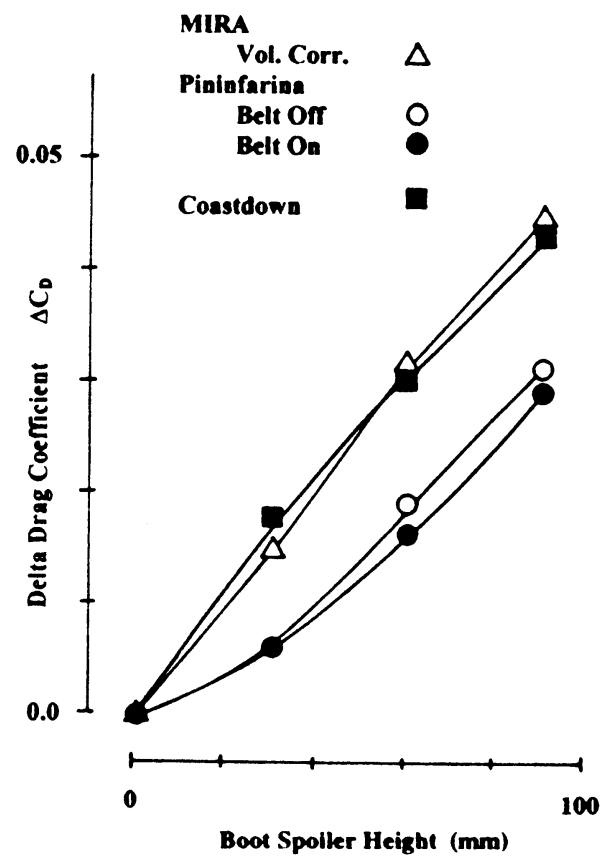

Figure 8. Incremental effect of boot spoilers - smooth floor
Figure 9 shows all of the boot spoiler data plotted on curves of drag coefficient against total lift coefficient related to the drag minimum condition. These are of the same parabolic shape as previously reported from earlier test results (17), and show that the data collapses to a common curve. The lift data is derived from the respective wind tunnels but the track data assumes MIRA wind tunnel values. This is acceptable in this case as the lift variation due to configuration change has been shown to be largely independent of wind tunnel and ground simulation. For both the vehicle underfloor conditions, when moving away from the drag minimum, a large change in drag is generated from a small change in lift. For the car with the standard floor, the data collapse is good and all techniques show a similar drag minimum configuration. When the vehicle is fitted with a smooth underfloor there is little change in the drag minimum condition for both Pininfarina cases. However, for the track and MIRA wind tunnel data, there is an apparent shift in the configuration required for minimum drag. The reasons for this are unclear.

FRONT SPOILER SERIES - A series of simple front spoilers were added to the base vehicle. Figure 10 shows the variation of absolute drag coefficient with the depth of the front spoiler. For the MIRA and Pininfarina stationary belt tests, this shows that drag decreases until an optimum depth is reached, followed by a rise in drag. For the on-road data and the moving belt data at Pininfarina, the drag is shown to continue falling with depth of front spoiler. It should be noted that, at Pininfarina, the front of the test vehicle overhung the leading edge of the belt. This resulted in the spoilers being $260 \mathrm{~mm}$ in front of the belt but in the region where the floor boundary layer is controlled by the tangential blowing system.

Figure 11 shows the incremental drag coefficient due to depth of front spoiler. This graph clearly shows the close agreement of the stationary belt and fixed floor tests. These two test methods fail, however, to show the continuing reduction in drag with the deeper front spoilers as measured on the track. Only the Pininfarina moving ground facility has a similar trend. This suggests that front spoiler optimisation can only be conducted in the wind tunnel with a moving belt system. It should be remembered, however, that the range of spoilers tested here were significantly deeper than would be considered practical for most production cars. The deepest of these arrangements resulted in a very small ground clearance of $35 \mathrm{~mm}$. 


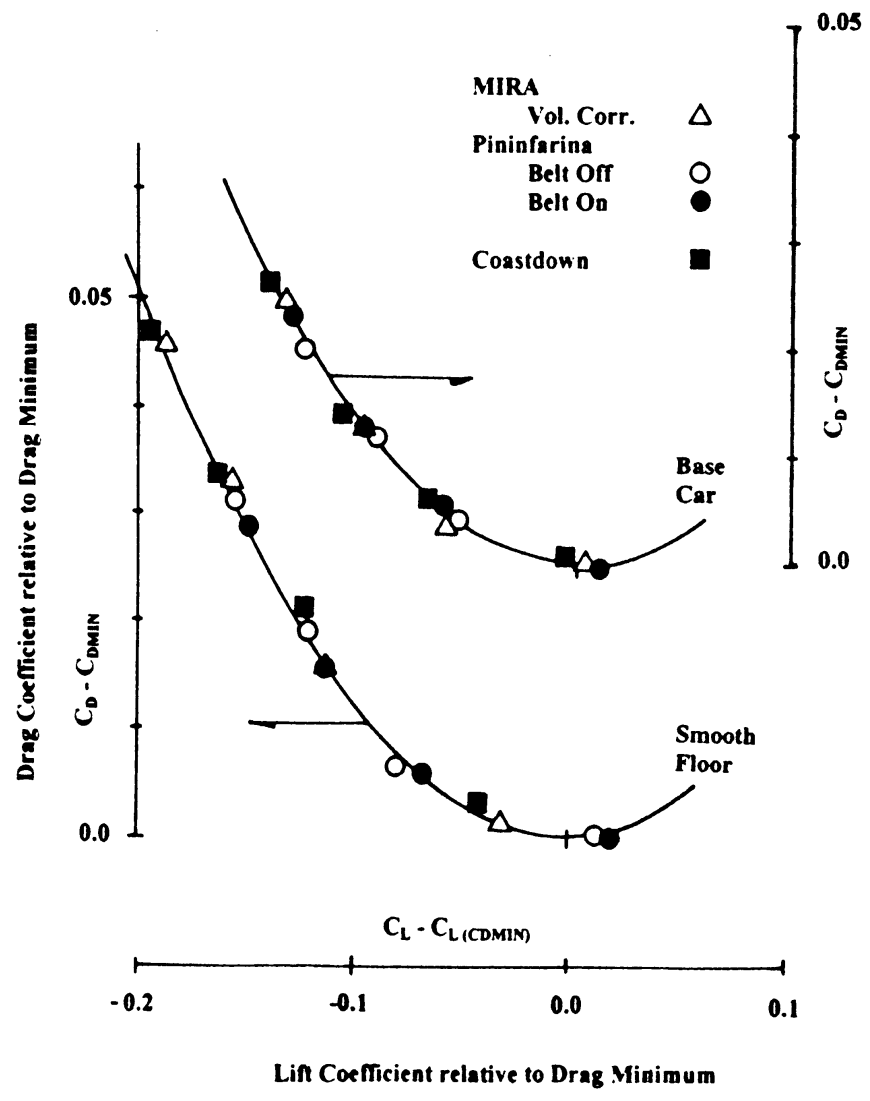

Figure 9. Drag versus lift for boot spoilers

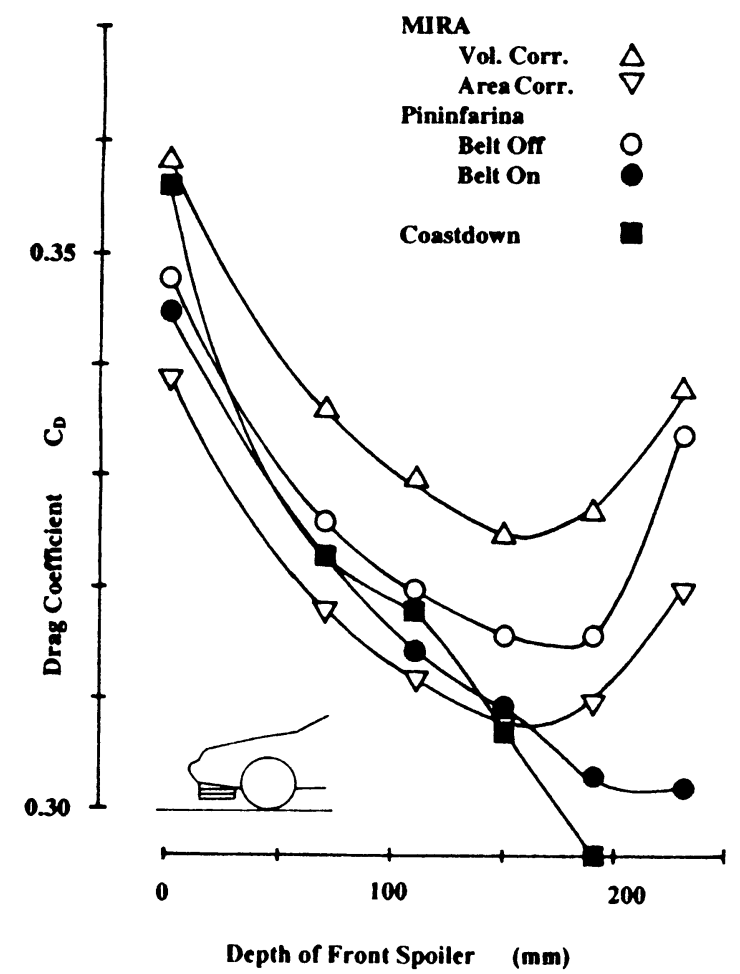

Figure 10. Effect of front spoilers

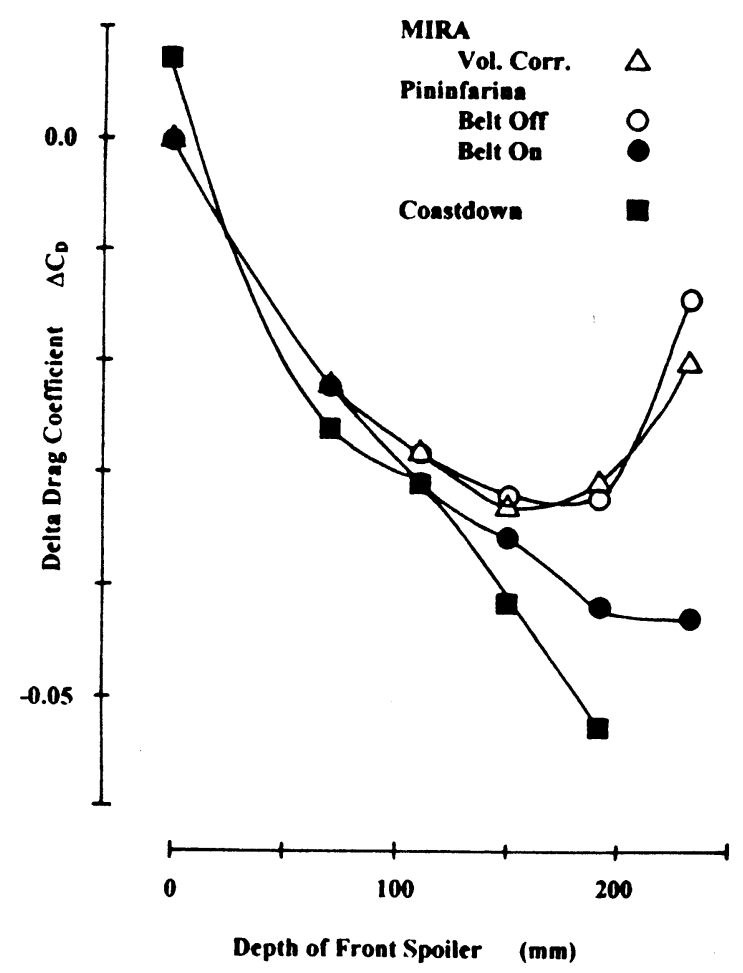

Figure 11. Incremental effect of front spoilers

SMOOTH UNDERFLOOR PANELS - Figures 12 and 13 show the effects on drag of progressively adding smooth panels to the underfloor. With any of the underfloor panels fitted, there is a difference between the Pininfarina moving and stationary belt results. The moving ground values are noticeably less than those for the stationary belt case. Both the continuity corrected MIRA values and track data lie between the two Pininfarina sets of results.

Figures 12 and 13 also show a noticeable difference between the on-road data and stationary ground wind tunnel cases when the rearmost panel and the front panel are fitted. For the rearmost panel the on-road data shows a drag increase when this panel is added. In the MIRA wind tunnel and the stationary belt results from Pininfarina, a drag reduction is shown. For the front panel, a significantly greater reduction in drag is shown by the on-road results compared with those from the MIRA and stationary belt Pininfarina results. The trends for the Pininfarina moving ground system, however, show good agreement with the on-road data. These trends are shown more clearly in Figure 13. In the middle of the car, the incremental drag due to the smooth underfloor panels is similar for all test techniques. 


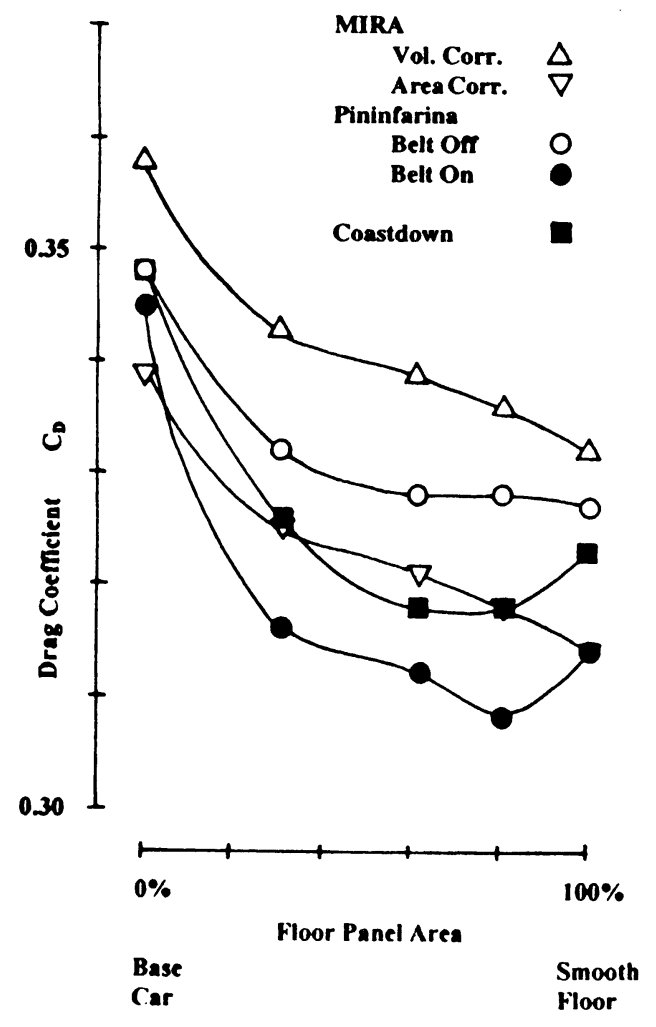

Figure 12. Effect of underfloor panels

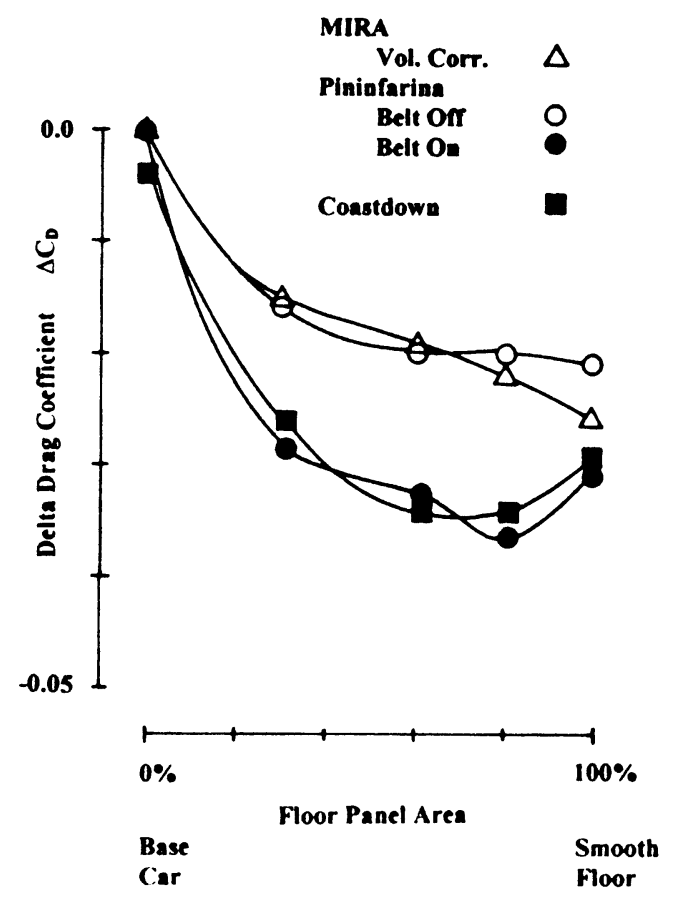

Figure 13. Incremental effect of underfloor panels

\section{FURTHER DISCUSSION}

In some cases, as illustrated by Figure 5, it appears that a simple incremental correction factor to take account of ground condition may be applied although the exact value of the correction may be tunnel dependent. Unfortunately, the effects of the boot spoilers when used in conjunction with the smooth underfloor, as shown in Figure 7 , require different correction factors. Thus there is no single simple correction factor which accounts for ground condition. The differences between wind tunnel and track data are both configuration and tunnel dependent.

The Pininfarina moving ground system does show significant advantages over conventional fixed ground wind tunnel testing when specific areas of the car, such as the front lower valence and underfloor, are to be aerodynamically optimised. Although the trends due to configuration changes are correct, in absolute correlation with track derived data, the Pininfarina moving ground results show some configuration dependency. This may be due to the physical limitations imposed by the dimensions of the moving belt. The effects due to the size of a moving belt have been investigated at model scale by Cooper et al (19) and Carr (20). These authors have reported that, in general, drag measurements are reduced with reduction of belt width. These findings conflict slightly with Mercker et al (6) where the effects of belt width at full-scale seem to have only a small effect on measured drag. Carr (20) also reported that reducing the length of the belt, in general, also had the effect of reducing measured drag. From these results it may be possible to infer that the physical dimensions of the belt will limit the absolute agreement of the Pininfarina data with that derived from the track tests.

The effect of belt length on drag, for the full-scale moving ground is of particular interest since the test vehicle overhung the belt. This may be of concern, particularly where the front spoiler is very deep and may be subject to interference with the tunnel floor boundary layer. At Pininfarina, however, the tangential blowing system may negate these concerns. For shorter vehicles, where the front does not overhang the belt the problem may not arise.

Finally, it is worth emphasising that the results reported and discussed above have been obtained for one particular European three-box style test vehicle. While this has included a range of aerodynamic configurations, it is recognised that there is a need to test different sizes and types of vehicle. 
Full-scale testing of a European passenger car, in a range of aerodynamic configurations, has been conducted on the track and in the Pininfarina and MIRA wind tunnels. In the Pininfarina wind tunnel, tests were carried out using the moving belt with the wheels rotating and the stationary belt with stationary wheels. Results from these various test techniques allow the following conclusions to be drawn :

- For the base car condition, the average drag coefficient derived from coastdown data was 0.009 greater than that measured in the MIRA wind tunnel (standard continuity blockage correction) and 0.002 greater than that in the Pininfarina wind tunnel in the moving ground case.

Analysis of the trends shows that:

- For the boot spoiler series with the standard (rough) underfloor, the wind tunnel data agrees closely with that derived from the track.

- For the boot spoiler series with the smooth floor, wind tunnel data from MIRA shows reasonable agreement with track data. Results from Pininfarina show a smaller change of drag for a given spoiler height, and there is only a small difference between the moving ground and stationary belt cases.

- For the range of front spoilers, all the wind tunnel results show good agreement with track data for the effects of small spoilers. When the spoiler becomes very deep only the Pininfarina moving ground system approaches the trend found on the track.

- For the underfloor panels, the Pininfarina moving ground system gives similar trends as the track derived data. The MIRA wind tunnel and Pininfarina stationary belt results under-predict the effect of the front panel and show opposite effects for the rear diffuser panel.

Most significantly, the results for this vehicle show that :

- A moving belt system is required for the aerodynamic optimisation of passenger car underfloors and for deep front spoilers.

\section{ACKNOWLEDGEMENTS}

The authors wish to thank Rover Group Limited, Loughborough University and Industrie Pininfarina SpA for permission to publish this paper. Thanks are also extended to Mr. C. Sherwin (Rover Group Aerodynamics) and the staff of the Pininfarina and MIRA Wind Tunnels for their help during the test programme. In addition, the authors pay special tribute to the late Mr. G. W. Carr (MIRA) who gave so much help, advice and encouragement during this work.
1. COGOTTI, A. Aerodynamic Characteristics of Car Wheels. Int J. of Vehicle Design, Technological Advances In Vehicle Design, pp 173-196 (1983).

2. BONIS, B. Aerodynamics of Wheels and Tires. Interface Vehicule-Sol/Road/ Vehicle Interface. Monte-Carlo, 23rd25th January 1989.

3. MERCKER, E. and KNAPE, H.W. Ground Simulation With Moving Belt and Tangential Blowing for Full-Scale Automotive Testing in a Wind Tunnel. SAE Paper 890367, Detroit (1989).

4. MERCKER, E., BREUER, N., BERNEBURG, $H$. and EMMELMANN, H-J., On the Aerodynamic Interference Due to the Rolling Wheels of Passenger Cars. SAE Paper 910311, Detroit (1991).

5. MERCKER, E. and BERNEBURG, H. On the Simulation Of Road Driving of a Passenger Car in a Wind Tunnel Using a Moving Belt and Rotating Wheels. Proceedings of Florence ATA Conference 1992.

6. MERCKER, E., SOJA, H. and WIEDEMANN, J. Experimental Investigation on the Influences of Various ground Simulation Techniques on a Passenger Car. Proceedings of Vehicle Aerodynamics Conference. The Royal Aeronautical Society, Loughborough, July (1994).

7. WIEDEMANN, J. The Influence of Ground Simulation and Wheel Rotation on Aerodynamic Drag Optimization Potential for Reducing Fuel Consumption. SAE Paper 960672, Detroit (1996).

8. WICKERN, G., ZWICKER, K. and PFADENHAUER, M. Rotating Wheels - Their Impact on Wind Tunnel Test Techniques and on Vehicle Drag Results. SAE Paper 970133, Detroit (1997).

9. COGOTTI, A. et al, Comparison Tests Between Some FullScale European Automotive Wind Tunnels - Pininfarina Reference Car. SAE Paper 800139, Detroit (1980).

10. BUCHHEIM, R. et al, Comparison Tests Between Major European Wind Tunnels. SAE paper 800140, Detroit (1980).

11. COSTELLI, A. et al. FIAT Research Centre Reference Car Correlation Tests Between Four Full Scale European Wind Tunnels and Road. SAE Paper 810187, Detroit (1981).

12. CARR, G.W. Correlation of Aerodynamic Force Measurements in MIRA and Other Automotive Wind Tunnels. SAE Paper 820374, Detroit (1982).

13. HOWELL, J.P. and HAYNES, T.L. Wind Tunnel Correlation. Rover Internal Report. October 1991.

14. COGOTTI, A. Ground Effect Simulation for Full-Scale Cars in the Pininfarina Wind Tunnel. SAE Paper 950996, Detroit (1995)

15. BUCKLEY, F. ABCD - An Improved Coast Down Test and Analysis Method. SAE Paper 950626, Detroit (1995).

16. PASSMORE, M.A. and LE GOOD, G.M. A Detailed Drag Study Using The Coastdown Method. SAE Paper 940420, Detroit (1994).

17. LE GOOD, G.M. et al On-Road Aerodynamic Drag Measurements Compared With Wind Tunnel Data. SAE Paper 950627, Detroit (1995).

18. MERCKER, E.and WIEDEMANN, J. On the Correction of Interference Effects in Open Jet Wind Tunnels. SAE Paper 960671, Detroit (1996).

19. COOPER., K.R., FEDIW, A.A. and GARY, K.P. Development of a Moving Ground Belt System for the Study of Vehicle Aerodynamics. Proceedings of Vehicle Aerodynamics Conference. The Royal Aeronautical Society, Loughborough, July (1994).

20. CARR, G.W. Influence of Moving-Belt Dimensions on Vehicle Aerodynamic Forces. Proceedings of MIRA International Vehicle Aerodynamics Conference, Birmingham, October (1996). 